\title{
Variation in echolocation calls produced by Myotis velifer (Chiroptera: Vespertilionidae) during postnatal development
}

\author{
Fabrizio Varela-Boydo ${ }^{1}$, luis Gerardo Ávila-Torresagatón ${ }^{1}$, Areli Rizo-Aguilar ${ }^{1}$, and José Antonio Guerrero ${ }^{1 *}$ \\ Facultad de Ciencias Biológicas, Universidad Autónoma del Estado de Morelos. Av. Universidad 1001, Cuernavaca, Morelos 62209, \\ México. fabriziovarela@hotmail.com (FVB), luis.avila@uaem.mx (LGAT), areli.rizo@uaem.mx (ARA), aguerrero@uaem.mx (JAG) \\ * Corresponding author
}

\begin{abstract}
This work describes the echolocation pulses produced by Myotis velifer during postnatal development. The aim was to record the changes of these calls during the development of this bat species and investigate the underlying causes. Bat specimens were sampled in El Salitre cave, Morelos, Mexico, during May and June 2016, where juvenile bats were captured and sorted into five age classes. Forearm length was used as reference for offspring growth. Each juvenile bat was induced to fly and the echolocation calls produced were recorded using an ultrasound detector. Six quantitative characteristics of the echolocation pulses of each call were measured, which served as reference to explore the development of this system during growth through a linear regression. A steady increase in the frequency parameters associated with bat growth was observed, coupled with a decrease in the temporal parameters. The final pulse frequency was the only parameter that remained unchanged during postnatal growth. The major changes in the characteristics of echolocation pulses during postnatal growth in $M$. velifer follow the pattern observed in other species previously studied. These changes are likely related to the development of organs and muscles involved in the emission and reception of sound, and to the learning process involved in the use of this adaptation.

En este trabajo realizamos grabaciones de los sonidos de ecolocalización de Myotis velifer con el propósito de describir los cambios que ocurren en las caractetrísticas de los pulsos durante su crecimiento postnatal. Realizamos muestreos en la cueva El Salitre, Morelos, México durante mayo y junio del 2016, donde se capturaron las crías y se clasificaron en cinco clases de edad. La longitud del antebrazo se utilizó como indicador del crecimiento de las crías. Fuera de la cueva, los individuos fueron liberados o forzados a intentar el vuelo para obtener las grabaciones de sus ultrasonidos utilizando un detector ultrasónico. Se midieron seis características cuantitativas de los pulsos de ecolocalización de cada individuo, las cuales sirvieron como referencia para estudiar el desarrollo de este sistema durante el crecimiento por medio de una regresión lineal. Los resultados mostraron un aumento progresivo en los parámetros de frecuencia asociado al crecimiento de las crías, así como una disminución en los parámetros temporales. La frecuencia final fue el único parámetro que no mostró modificaciones significativas durante el crecimiento postnatal. Los cambios notables en las características de los pulsos de ecolocalización durante el crecimiento posnatal de $M$. velifer siguen el patrón observado de especies anteriormente estudiadas. Es posible que estos cambios estén relacionados con el desarrollo de los órganos y músculos involucrados en la emisión y recepción del sonido y el aprendizaje del uso de esta adaptación.
\end{abstract}

Key words: Age; bat; El Salitre cave; ontogeny; ultrasound.

(C) 2019 Asociación Mexicana de Mastozoología, www.mastozoologiamexicana.org

\section{Introduction}

Most bats rely on the emission of echolocation calls for survival. In aerial insectivorous species, individuals must be capable of producing high-frequency sounds and process spatial information from the echoes produced in order to catch insects successfully during their early flights (Moss et al. 1997). Thus, sounds emitted during the first days after birth may be the precursors of echolocation behavior in adult bats (Moss et al. 1997; Zhang et al. 2005). In most cases, there is a correlation between postnatal development and the type of calls emitted by young bats (Brown and Grinnell 1980). In general, young bats emit long-duration, high-intensity and low-frequency pulses, relative to the sounds emitted by adults (Brown and Grinnell 1980; Rubsamen 1987; Monroy et al. 1995; Zhang et al. 2005; Liu et al. 2007). This differentiation of pulses between bats of different age might make it easier for juveniles to recognize adult individuals and follow them to suitable foraging grounds (Kazial et al. 2001).

Works describing the development of vocalizations during postnatal growth, which include species of families Ves- pertilionidae (Moss et al. 1997; Zhang et al. 2005), Hipposideridae (Habersetzer and Marimuthu1986), Rhinolophidae (Rubsamen 1987; Liu et al. 2007), Noctilionidae (Brown et al. 1983), Mormoopidae (Veter et al. 2003) and Phyllostomidae (Carter et al. 2013) show a general pattern in the development of echolocation, consisting of a steady increase in frequencies and a reduction of the temporal patterns of pulses. In Mexico, there is virtually no research work addressing the relationship between postnatal growth and the development of echolocation. In this sense, the maternity colony of $M$. velifer that congregates each year at El Salitre cave, Morelos, offers an opportunity to describe in quantitative terms the pulses of echolocation calls produced by Myotis velifer (J. A. Allen, 1890), a species widely studied in United States but not in Mexico, during postnatal growth.

\section{Methods}

The study was conducted during June and July, 2016, in El Salitre cave, located in the municipality of Tlaltizapán, Morelos, Mexico ( $18^{\circ} 45^{\prime} 00.3^{\prime \prime} \mathrm{N}, 99^{\circ} 11^{\prime} 23.3^{\prime \prime} \mathrm{W}$ ). Individuals (juvenile and adult bats) were captured with a hand net 
in the maternity colony that is established each year inside the cave, and were subsequently placed inside cotton cloth bags. After capture, the forearm length (FL) of each individual was measured with a CD-8"CS digital caliper (Mitutoyo Corporation, Japan); additionally, each individual was sexed and sorted into one of 5 age categories (see Results), according to the ossification of phalanges, morphological traits and ability to fly.

A flight simulation experiment was conducted outside of the cave, consisting in rising each individual bat up to a height of two meters, and then dropping it in front of a full-spectrum Echo Meter 3+ ultrasound detector (Wildlife Acoustics, Inc, USA.) set up to record at a sample rate 256 $\mathrm{kHz} / 16-$ bit resolution and a $1 \mathrm{x}$ time expansion (real time). The detector was placed at two meters from the drop point with an inclination of $40^{\circ}$ to ensure the capture and recording of echolocation pulses emitted by each bat released. To avoid potential injuries to individuals who were unable to fly, a soft surface was placed on the landing area. This technique has been used in previous studies to record vocalizations of juvenile bats with no reports of apparent harm (e.g. Moss et al. 1997). At the end of the sound recordings, juveniles that were unable to fly were returned to the nursery colony by placing them in the same site of capture, while those able to fly entered the cave by themselves.

The recordings were analyzed using the software BatSound Pro 3.30 (Pettersson Elektronik, AB, Sweden). From the acoustic files, high-quality echolocation sequences were selected (those with an energy of at least $20 \mathrm{~dB}$, as measured within the power spectrum) and with more than 10 pulses. By means of an expanded-time spectrogram (10x), a 16-bit resolution, a sample rate of $22,050 \mathrm{kHz}$, and using a Hanning-type window with 1024 Fourier transformations (FFT) and 95\% overlap (Rizo-Aguilar et al. 2015), six quantitative characteristics of pulses were measured according to the diagram and description of Rivera-Parra and Burneo (2013): initial frequency, mid-pulse frequency, final frequency, bandwidth, duration, and interval. A sequence involving between 10 and 20 pulses was measured from each individual bat to record variations in each bat evaluated. Statistical analyses were conducted using the average values of each characteristic measured.

The changes in the variables of echolocation pulses were related to postnatal growth of offspring using forearm length as an indicator of age (Rajan and Marimuthu 1999; Sharifi 2004). The relationship between the changes in the pulse parameters measured and the increase in forearm size was described through a simple linear regression analysis for each variable using the program Statistica (Statsoft 2001 7); outlier data were previously eliminated through a exploratory data analysis. In order to meet the normality assumption, data were transformed to natural logarithms.

\section{Results}

A total of 136 individuals were captured ( 75 females and 61 males). Of these, 21 had no hair and had not opened the eyes yet ( $=23.35 \mathrm{~mm}$, class 1$) ; 35$ showed signs of hair and teeth growth, and during the recording experiment these individuals fluttered before and during the fall ( $L A=28.99$ $\mathrm{mm}$, class 2); 43 had well-defined teeth and pelage, but were unable to fly (LA $=37.63 \mathrm{~mm}$, class 3$) ; 26$ showed nonossified phalanx epiphyses but were able to fly ( $L A=64.95$ $\mathrm{mm}$, class 4 or subadults); and 11 were considered as adults ( $=44.81 \mathrm{~mm}$, class 5).

The echolocation pulses of $M$. velifer during postnatal growth are short-lasting and of modulated frequency (Figure 1). In case of class-1 juvenile bats, the initial frequency was relatively low $(=56.86 \mathrm{kHz}$ ) compared with the one used by class- 5 individuals $=83.73 \mathrm{kHz}$ ). Similarly, the bandwidth changed over time, with a steady increase in the range of frequencies used from class 1 ( $=24.33 \mathrm{kHz}$ ) to class 5 ( $=50.52 \mathrm{kHz}$ ). By contrast, the duration of pulses was reduced drastically from class 1 to class 2, shifting from 11.58 to $4.71 \mathrm{~ms}$. From class 2, the duration of pulses showed a slight variation. The mean range shifted from $152.11 \mathrm{~ms}$ for class-1 to $93.64 \mathrm{~ms}$ for class- 5 bats.

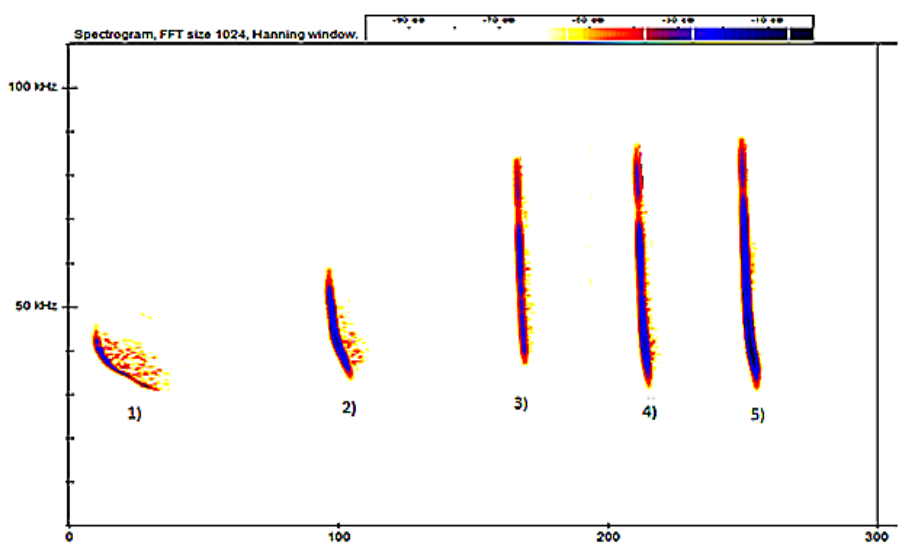

Figure 1. Spectrogram relating postnatal development of $M$. velifer to the characteristics of echolocation calls in each age class: 1) young bats still lacking hair and teeth (Forearm length, LA $=23.35 \mathrm{~mm}$ ), 2) young bats showing signs of hair and teeth growth ( $(\mathrm{LA}=28.99 \mathrm{~mm}), 3$ ) young bats showing well-defined pelage and teeth, but unable to fly $(L A=37.63 \mathrm{~mm})$, sub-adults $(L A=44.32 \mathrm{~mm})$, adults $(L A=44.83 \mathrm{~mm})$.

The statistical analyses (Table 1) showed a significant positive relationship $(P<0.001)$ between forearm length and initial frequency, mid-pulse frequency, and bandwidth, indicating that these variables increased as juvenile bats grew. In addition, there was a significant negative relationship $(P<0.001)$ between forearm length and the duration and interval of pulses, indicating that the time parameters of pulses decreased as juvenile bats grew. However, in the case of the final pulse frequency there was no correlation $(P=0.879)$ with forearm length of juvenile bats; hence, this variable remained virtually unchanged throughout the early growth stages to adulthood.

\section{Discussion}

Our results show that the postnatal development of echolocation in $M$. velifer follows a pattern that resembles the one described for other bat species, consisting in a steady rise in frequencies and a shortening in the temporal patterns of pulses as juvenile bats grow (Brown and Grinnell 
Table 1. Results of the regression analyses between forearm length $(\mathrm{FL})$ and initial pulse frequency (IF), final pulse frequency (FF), mid-pulse frequency (MF), bandwidth (BW), pulse duration, and interval between pulses. Values corresponding to the (F) statistic, degrees of freedom (d. f.), significance value $(P)$, and coefficient of determination $\left(r^{2}\right)$.

\begin{tabular}{lrrrr}
\hline Regression & \multicolumn{1}{l}{$\boldsymbol{F}$} & $\boldsymbol{d . f}$. & \multicolumn{1}{l}{$\boldsymbol{P}$} & \multicolumn{1}{l}{$\mathbf{r}^{\mathbf{2}}$} \\
\hline FL vs IF & 64.898 & 1,84 & $<0.001$ & 0.435 \\
FL vs FF & 0.231 & 1,84 & 0.879 & 0.002 \\
FL vs MF & 16.357 & 1,84 & $<0.001$ & 0.662 \\
FL vs BW & 83.964 & 1,84 & $<0.001$ & 0.599 \\
FL vs Duration & 33.244 & 1,84 & $<0.001$ & 0.583 \\
FL vs Interval & 90.130 & 1,84 & 0.001 & 0.517 \\
\hline
\end{tabular}

1980; Brown et al. 1983; Habersetzer and Marimuthu1986; Rubsamen 1987; Moss et al. 1997; Liu et al. 2007).

The youngest (class 1 ) bats emitted sounds of relatively low frequencies and long duration, compared to pulses emitted by adults (initial frequency, 44.5-91.6 kHz). These calls may be the precursors of echolocation sounds used by adults, that is, there is likely a gradual learning process in the use and modulation of the high frequencies (Moss et al. 1997; Zhang et al. 2005). The adjustment of increasing frequencies could also be due to the maturation of the larynx. For instance, it is known that in vespertilionid bats, the frequency and duration of calls are controlled by the contraction and relaxation of the cricothyroid muscles surrounding the larynx and controlling the strain of the vocal cords (Gould 1975; Moss et al. 1997).

These findings also revealed a steady increase in the bandwidth of echolocation pulses as juvenile bats grow. The modulated frequency and broadband pulses recorded for subadults (class 4) and adults (class 5) allow the precise location of prey and provide information related to its shape and texture (Schnitzler and Kalko 2001; Altringham 2011). In particular, the increased bandwidth may be related to the development of the echolocation system to capture insects in closed environments as bats grow and feed by themselves.

The drastic reduction in the temporal parameters of pulses throughout the postnatal development of juvenile bats can be attributed to the maturation of the organs involved in sound emission and reception (Monroy et al. 1995; Moss et al. 1997), or to the learning process to interpret the information transmitted by the echoes of calls emitted, as both pulse duration and the interval between pulses are adjusted according to the distance between the bat and its hunting target (Neuweiler, 2000).

\section{Acknowledgments}

The authors wish to thank José Varela, owner to the land where El Salitre cave is located, for allowing us access to conduct this investigation. Thanks also to our laboratory fellows I. Ariza Reynoso, R. Carmona, E. Farfán Estrada, B. González Zariñana, and A. Lara Núñez, for their support in bat captures and recordings. María Elena Sánchez-Salazar translated the manuscript into English.

\section{Cited literature}

Altringham, J. D. 2011. Echolocation and other senses. Pp 6884 in Bats: From Evolution to Conservation (Altringham, J. D., ed.). Oxford University Press. Oxford, United Kingdom.

Brown, P. E., AND A. D. GrinNell. 1980. Echolocation ontogeny in bats. Pp. 355-377 in Animal Sonar Systems (Busnel, R., and J. F. Fish, comps). Plenum Press. New York, U. S. A.

Brown, P. E., T. W. Brown, AND A. D. GRINnELL. 1983. Echolocation, development, and vocal communication in the lesser bulldog bat, Noctilio albiventris. Behavioral Ecology and Sociobiology 13:287-298.

Carter, R. T., J. B. Shaw, and R. A. Adams. 2013. Ontogeny of vocalization in Jamaican fruit bats with implications for the evolution of echolocation. Journal of Zoology 293:25-32.

GouLD, E. 1975. Neonatal vocalizations in bats of eight genera. Journal of Mammology 56:15-29.

Habersetzer, J., AND G. Marimuthu. 1986. Ontogeny of sounds in the echolocating bat Hipposideros speoris. Journal of Comparative Physiology 158:247-257.

KaZIAL, K. A., S. C. BuRnEtT, AND W.M. MASTeRS. 2001. Individual and group variation in echolocation calls of big brown bats, Eptesicus fuscus (Chiroptera: Vespertilionidae). Journal of Mammalogy 82:339-351.

LIU, Y., J. FenG, Y. L. JIANG, L. WU, AND K. P. SUn. 2007. Vocalization development of greater horseshoe bat, Rhinolophus ferrumequinum (Rhinolophidae, Chiroptera). Folia Zoologica 56:126-136.

Monroy, J. A., M. E. Carter, K. E. Miller, and E. Covey. 1995. Development of echolocation and communication vocalizations in the big brown bat, Eptesicus fuscus. Journal of Comparative Physiology 197:459-467.

Moss, C. F., D. Redish, C. Gounden, And H. T. Kunz. 1997. Ontogeny of vocal signals in the little brown bat, Myotis lucifugus. Animal Behaviour 54:131-141.

Neuweller, G. 2000. Echolocation. Pp. 140-260 in The Biology of bats (Neuweiler, G., ed.). Oxford University Press. Oxford, U. S. A.

RAJAN, K. E., AND G. Marimuthu. 1999. Postnatal growth and age estimation in the Indian false vampire bat (Megaderma lyra). Journal of Zoology 248:529-534.

Rivera-Parra, P., and F. S. Burneo. 2013. Primera biblioteca de llamadas de ecolocalización de murciélago del Ecuador. Therya 4:79-88.

Rizo-Aguilar, A., L. G. Ávila-Torresagatón, L. Fuentes-Vargas, A. C. Lara-Nuñez, G. I. Flores Nuñez, and S. Albino-Miranda. 2015. Técnicas para el estudio de los murciélagos. Pp 163-188 in Manual de técnicas del estudio de la fauna (Gallina-Tessaro, S., ed.). Instituto de Ecología, A. C., Xalapa, México.

RüBsAmen, R. 1987. Ontogenesis of the echolocation system in the rufous horseshoe bat, Rhinolophus rouxi (audition and vocalization in early postnatal development). Behavioral Ecology and Sociobiology 161:899-913.

SChNITZLER, H. U., AND E. K. V. KalKo. 2001. Echolocation by insecteating bats: We define four distinct functional groups of bats and find differences in signal structure that correlate with the typical echolocation tasks faced by each group. BioScience 51:557-569.

SHARIFI, M. 2004. Postnatal growth in Myotis blythii (Chiroptera, Vespertilionidae). Mammalia 68:283-289. 
StATSOFT. 2001. STATISTICA (data analysis software system). StatSoft, Inc., Tulsa, U. S. A.

Vater, M., M. Kössl, E. Foeller, F. Coro, E. Mora, and I. J. Russell. 2003. Development of echolocation calls in the mustached bat, Pteronotus parnellii. Journal of Neurophysiology 90:2274-2290.

Zhang, L., G. Jones, S. Parsons, B. Liang, and S. Zhang. 2005. Development of vocalizations in the flat-headed bats, Tylonycteris pachypus and $T$. robustula (Chiroptera: Vespertilionidae). Acta Chiropterologica 7:91-99.

\section{Associated editor: Rafael Avila}

Submitted: Agust 8, 2018; Reviewed: November 13, 2018;

Accepted:December 12, 2018; Published on line: January 16, 2019. 